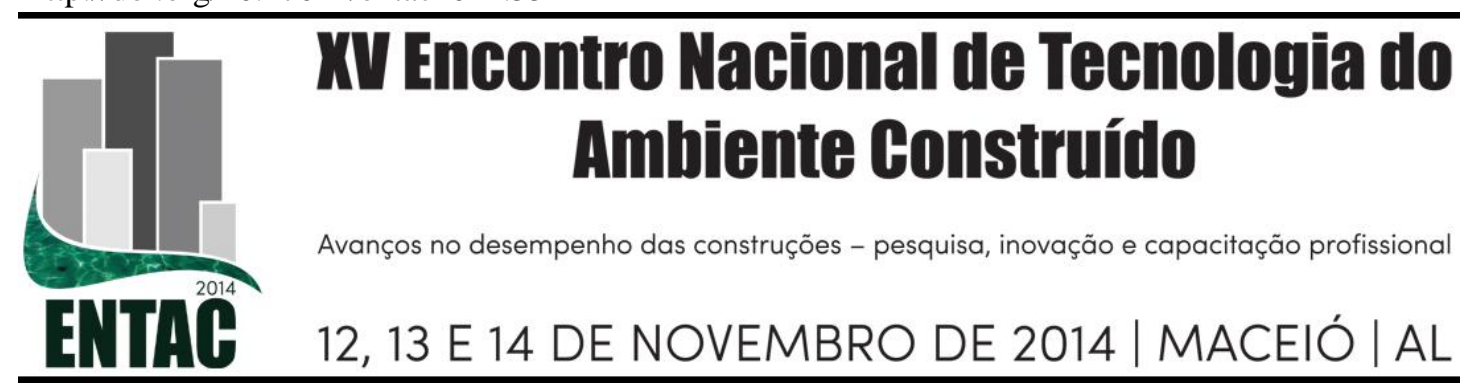

\title{
CONFORTO AMBIENTAL EM INSTITUIÇÕES DE ENSINO: ANÁLISE DO CAMPUS DO SERTÃO DA UFAL
}

\author{
PEREIRA SANTOS, Kerolaynh (1); MARTINS DA COSTA, Gleidson (2); \\ BARROS, Bruna Rosa (3) \\ (1) UFAL, kerolaynhsantos@gmail.com (2) UFAL, engcivil.gleidson@gmail.com, (3) UFRGS, \\ bruna.barros@ufrgs.br
}

\begin{abstract}
RESUMO
Os processos de ensino-aprendizagem são diretamente influenciados pelo conforto ambiental disponível nas instituições de ensino. Assim, o presente trabalho objetiva apresentar uma análise parcial dos aspectos construtivos e padrão arquitetônico das instalações da Sede do Campus do Sertão da Universidade Federal de Alagoas (UFAL), com sede em Delmiro Gouveia/AL, sob o ponto de vista dos confortos térmico e lumínico. Caracterizada como Estudo de Caso, esta pesquisa utiliza como procedimentos o levantamento bibliográfico e documental para estudo das condicionantes climáticas, recomendações técnicas construtivas adequadas à região e características projetuais do edifício, além de análise in loco. Desta forma, este trabalho é justificado pela escassez de estudos voltados às técnicas construtivas aplicáveis à região semiárida brasileira e pela perspectiva de intervenção, uma vez que poderá embasar projetos de readequação e expansão arquitetônica deste Campus e de outras construções na região.
\end{abstract}

Palavras-chave: Conforto ambiental, UFAL, Semiárido alagoano, Instituições de ensino.

\begin{abstract}
Teaching and learning processes are directly influenced by environmental comfort available in educational institutions. Thus, from the point of view of thermal and luminous comfort, this paper presents a partial analysis of the constructive aspects and architectural pattern of the Hinterland Campus of the Federal University of Alagoas (UFAL), in Delmiro Gouveia/AL. This research is characterized as a case study and uses procedures such as bibliographic and documentary survey to study climate aspects, technical constructive recommendations more appropriate to that region and design pattern of the building. Those studies are complemented by a local analysis. Even so, this paper is justified by the existence of few studies about construction techniques applicable to the Brazilian semiarid region and the prospect of intervention because it may be used to realignment projects and architectural expansion of that campus and other buildings in this region.
\end{abstract}

Keywords: Environmental comfort, UFAL, Semiarid region of Alagoas, Educational institutions.

\section{INTRODUÇÃ̃O}

O conceito de espaços habitáveis vem sofrendo mudanças significativas com o passar do tempo, em especial, no que se trata da satisfação do usuário. Estas alterações ocorrem devido à adoção de novos parâmetros de qualidade das edificações, os quais visam proporcionar melhorias no conforto ambiental e eficiência energética, através da utilização de métodos ambientalmente mais adequados.

Isso porque o uso de recursos naturais para condicionamento e iluminação de interiores promove a satisfação das necessidades biológicas e psicológicas do usuário em ritmos naturais e saudáveis, através da sua ligação com o ambiente exterior. Igualmente, o 
baixo consumo de energia elétrica contribui com a redução de impacto ambiental negativo gerado pela construção e manutenção das edificações (SILVA, 2009).

Cabe salientar que o conforto ambiental se refere à harmonia entre o usuário e as variáveis ambientais durante a realização das atividades cotidianas, proporcionada pelas características construtivas da edificação. Segundo Corbellas e Yannas (2003, p.37), a Arquitetura Bioclimática busca "prover um ambiente construído com conforto físico, sadio e agradável, adaptado ao clima local".

No que concerne às instituições de ensino, são imprescindíveis ao adequado desenvolvimento dos processos de ensino-aprendizagem que a comunicação seja compreendida, a visualização seja nítida e a climatização seja confortável. Logo, verifica-se que o conforto ambiental influencia diretamente no desempenho educacional do estudante (DALVITE et al, 2007; GEMELLI, 2009; SILVA, 2009).

Neste contexto, as instalações da Sede do Campus do Sertão da Universidade Federal de Alagoas (UFAL), inaugurada em março de 2010 no município de Delmiro Gouveia-AL, foram planejadas de modo a atender as características bioclimáticas da região. Contudo, cabe avaliar se elas efetivamente contemplam os requisitos projetuais definidos para $o$ clima quente e seco, e para um ambiente educacional.

Assim, o presente trabalho objetiva apresentar uma análise parcial dos aspectos construtivos das salas de aula da referida edificação sob o ponto de vista dos confortos térmico e lumínico. Desenvolvido pelos membros do Programa de Educação Tutorial PET Engenharias da UFAL no ano de 2012, este estudo é de cunho descritivo e se caracteriza pelo método de Estudo de Caso, tendo em vista que utiliza como procedimentos técnicos a pesquisa bibliográfica e documental, para estudo das características climáticas, recomendações técnicas construtivas adequadas para a região e características projetuais do edifício, além de análise in loco.

Diante do exposto, este trabalho é justificado pela escassez de estudos voltados às técnicas construtivas aplicáveis à região semiárida brasileira, e pela perspectiva de intervenção, uma vez que poderá embasar futuros projetos de readequação deste edifício, os quais contribuam com a melhoria do seu conforto ambiental, bem como balizar a expansão arquitetônica deste Campus e de outras construções nesta região.

\section{CARACTERIZAÇÃO DO OBJETO DE ESTUDO}

Distante $303 \mathrm{~km}$ da capital, Delmiro Gouveia está inserido na região semiárida do estado de Alagoas, localizando-se no extremo Oeste (Figura 1a). Com clima quente e seco, o município apresentou, entre os anos de 1975 e 2011, temperaturas médias que variam de $18,8^{\circ} \mathrm{C}$ a $30,1^{\circ} \mathrm{C}$ (AGRITEMPO, 2012). Ainda, baseado nos dados disponíveis no Zoneamento Bioclimático Brasileiro (ABNT, 2003), salienta-se que o município de Delmiro Gouveia melhor se enquadra na Zona 7.

Quanto às instalações da Sede do Campus do Sertão da UFAL (Figura 1b), elas foram ocupadas em outubro de 2011. Até o presente, apenas o edifício principal teve suas obras concluídas, onde se concentram as salas de aula, laboratórios, auditório, bibliotecas etc., totalizando $3522,10 \mathrm{~m}^{2}$ de área construída, o que representa cerca de $1,5 \%$ do terreno disponível, segundo o projeto arquitetônico do Campus (2009). No processo de avaliação deste trabalho, utilizou-se o projeto arquitetônico da edificação estudada, bem como foram feitas análises e registros fotográficos in loco.

Figura 1 - (a) Localização do município de Delmiro Gouveia no Estado de Alagoas, e (b) Destaque do bloco das salas de aula 


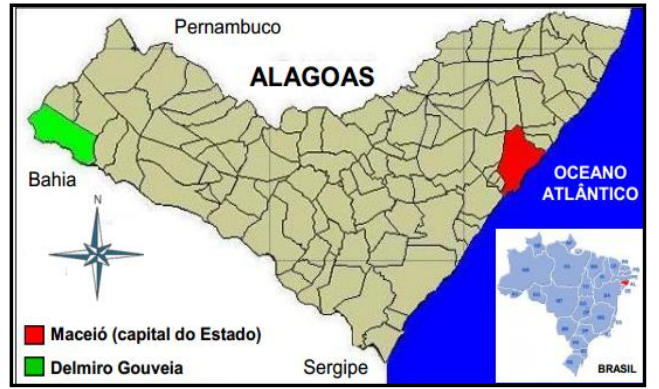

(a)

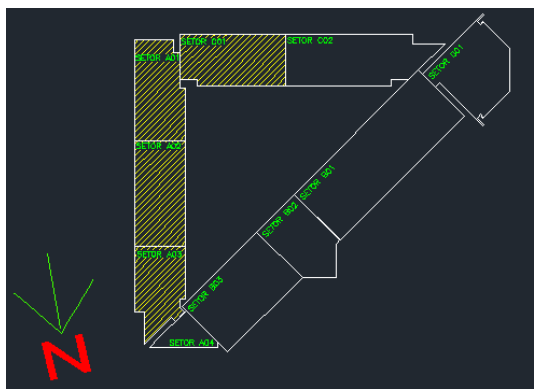

(b)

Fonte: (a) Adaptado de IBGE (2009) e (b) Adaptado do projeto arquitetônico do Campus do Sertão/UFAL (2009).

\section{ANÁLISE DO CONFORTO HIGROTÉRMICO}

Em uma instituição de ensino, o processo de ensino-aprendizagem pode ser interferido por vários fatores como, por exemplo, o desconforto dos alunos em relação às variações climáticas. Krügere; Zannin (2004) afirmam que perturbações no conforto térmico, como o calor excessivo, provocam cansaço e sonolência, e consequente redução no desempenho dos estudantes e professores. À luz disso, o ambiente de ensino deve ser projetado de modo a fornecer condições ambientais adequadas a partir do uso do arcondicionado ou por meios de condicionamento passivo. Entretanto, este último se sobressai, pois, além de gerar bem-estar psicológico, ajuda na redução no consumo de energia.

Diante do exposto, para a Arquitetura Bioclimática, a correta escolha dos materiais de construção, da definição do volume arquitetônico em função das condições climáticas locais, do uso de protetores solares exteriores, da possibilidade de captação da luz natural sem elevar excessivamente a carga térmica e do uso da ventilação natural são alguns dos quesitos que devem ser ponderados em uma edificação (BARBORA; LIMA, 2010). A Figura 2 representa a Carta Bioclimática da Zona 7, a qual embasa as diretrizes construtivas que melhor se adequam para região do semiárido (ABNT, 2003).

\section{Figura 2 - Carta Bioclimática para Zona 7}

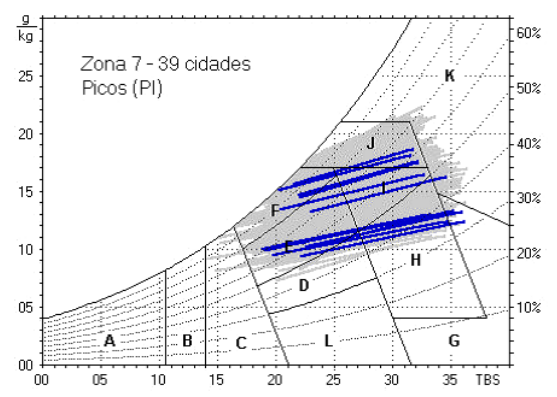

(A) aquecimento artificial; (B) aquecimento solar da edificação; (C) vedações internas pesadas; (D) zona de conforto térmico (baixa umidade); (E) zona de conforto térmico; (F) zona de desumidificações (renovação do ar); $(\mathrm{G}+\mathrm{H})$ zona de resfriamento evaporativo; $(\mathrm{H}+\mathrm{I})$ zona de massa térmica de refrigeração; $(\mathrm{I}+\mathrm{J})$ zona de ventilação; (K) zona de refrigeração artificial; (L) zona de umidificação artificial. A parte destacada em azul indica as estratégias que mais se adequam à região em estudo.

Fonte: ABNT (2003)

Com base na Carta Bioclimática da Zona 7, pode-se verificar que nas regiões de clima quente e seco a ventilação natural deve ser controlada para evitar incômodos aos usuários do prédio e propiciar a renovação do ar (SOUZA, 2006). Neste sentido, recomenda-se a ventilação seletiva. Diante disso, a melhor solução é permitir a ventilação cruzada nos períodos em que a temperatura interna seja maior que a externa e adotar janelas pequenas associadas às estratégias de sombreamento (ABNT, 2003).

Desta forma, para realizar o condicionamento passivo adequado na edificação, Batista (2006) indica restringir a ventilação durante o dia (ventilação de conforto), evitando a 
incidência direta da massa de ar quente nos usuários. Nestes termos, a ventilação natural é preferencial durante o período noturno (GIOVANI, 1991 apud ANDRADE, 1996). Vale salientar que o resfriamento convectivo noturno ajuda a eliminar o calor absorvido pela edificação durante o dia.

Para o aproveitamento adequado da ventilação, algumas normas são sugeridas. A dimensão das aberturas/janelas deve estar entre $10 \%$ e $15 \%$ em relação à área do piso de um determinado ambiente (ABNT, 2003). Na Figura 3 é possível observar o modelo de esquadria utilizado no edifício analisado.

Figura 3-Aberturas das salas de aula da UFAL, Campus do Sertão

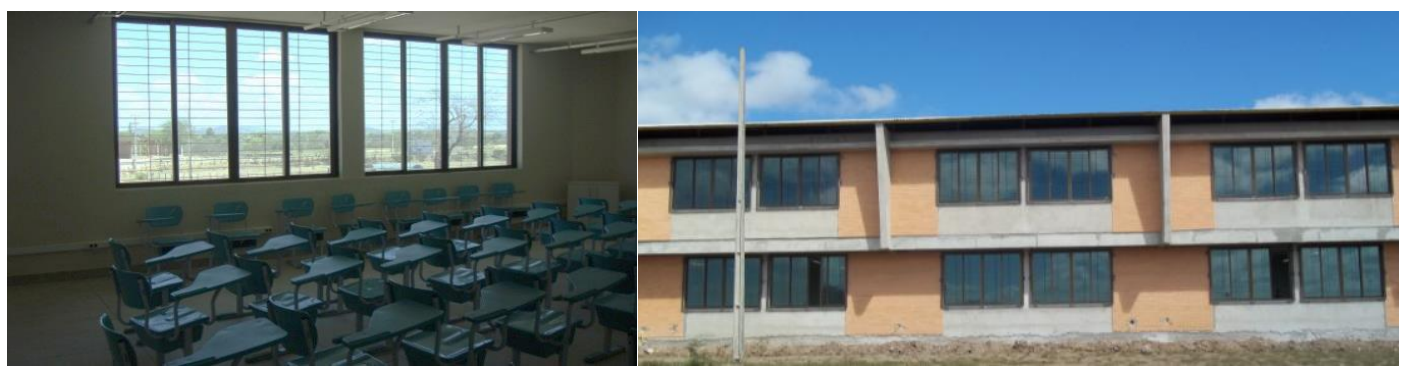

(a)

(b)

Fonte: (a) Os autores (2012) e (b) www.alagoasnanet.com.br

Na Tabela 1, observa-se o dimensionamento das janelas das salas de aula bem como o percentual das mesmas em relação ao piso de cada ambiente. Com base nisso, nota-se que o dimensionamento das janelas está maior do que o recomendado. Apesar da pequena variação, alguns problemas quanto ao conforto térmico podem ser agravados.

Tabela 1 - Dimensão das salas e janelas da sede do Campus do Sertão

\begin{tabular}{|c|c|c|c|c|}
\hline Salas & $\begin{array}{c}\text { Quantidade de } \\
\text { janelas por sala }\end{array}$ & $\begin{array}{c}\text { Área da sala } \\
\left(\mathbf{m}^{\mathbf{2}}\right)\end{array}$ & $\begin{array}{c}\text { Área total das } \\
\text { janelas }\left(\mathbf{m}^{\mathbf{2}}\right)\end{array}$ & $\begin{array}{c}\text { Percentual da área da janela } \\
\mathbf{e m ~ r e l a c ̧ a ̃ o ~ a ̀ ~ s a l a ~}(\%)\end{array}$ \\
\hline $01 ; 12$ & 3 & 64,70 & 13,10 & 20,2 \\
\hline 02 a 07 & 2 & 80,00 & 12,60 & 15,7 \\
\hline 09 & 1 & 39,40 & 6,30 & 16,0 \\
\hline $10 ; 13$ a 18 & 2 & 74,60 & 12,60 & 17,0 \\
\hline 11 & 2 & 61,00 & 12,60 & 20,6 \\
\hline 08 e 19 & 2 & 36,60 & 11,00 & 30,0 \\
\hline
\end{tabular}

Fonte: Elaborado a partir do projeto arquitetônico do Campus do Sertão/UFAL (2009)

Um dos incômodos, reflexo do mau dimensionamento e posicionamento das janelas, é a incidência da corrente de ar quente diretamente nas pessoas, devido ao clima da região, pois diminui a sensação de conforto dos usuários. As janelas grandes também propiciam a maior incidência dos raios solares dentro da sala, o que contribui para o aumento da temperatura no interior da sala e prejudica o desenvolvimento das atividades. Além disso, essa edificação não possui dispositivos de proteção solar e, assim, sugere-se a implantação de brises-soleil devido às vantagens que elas proporcionam para os edifícios que se encontram nas regiões de clima quente (GUTIERREZ; LABAKI, 2005). Dentre elas, destaca-se o controle e a redução do ganho de calor solar.

Entretanto, destaca-se que o edifício possui um sistema de chaminé que permite a alteração no processo de circulação da ventilação natural das salas de aula (Figura 4). O 
sistema citado funciona de acordo com a diferença de temperatura do ambiente interno e externo associado à diferença de pressão. O efeito chaminé é possível devido à variação de densidade da massa de ar quente e frio, pois, quando a temperatura interna é maior que a externa, o ar externo ingressa na edificação através das aberturas mais baixas, e o ar interno sai pelas aberturas mais elevadas (CHIARELLO, 2006).

\section{Figura 4 - Sistema de chaminé (a) Corte e (b) Vista da saída de ar na fachada}

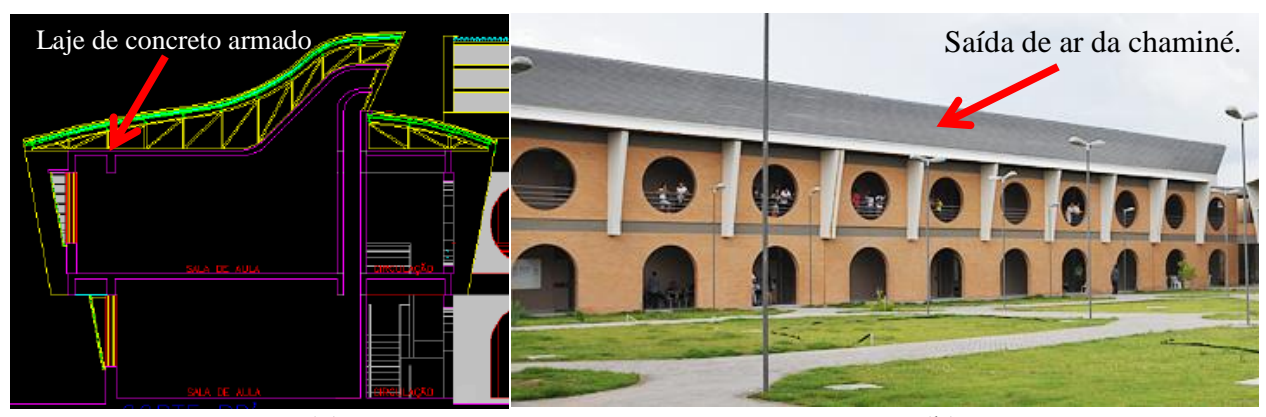

(a)

(b)

Fonte: (a) Adaptado do projeto arquitetônico do Campus (2009) e (b) www.alagoasnanet.com.br

Segundo Batista (2006), as aberturas devem ser voltadas para os ventos dominantes, pois elas coletam o vento em alturas onde sua temperatura e cargas de poeira são menores, e a velocidade é mais acentuada. Na região do sertão alagoano, a direção do vento é predominantemente entre SE e S (COSTA; LYRA, 2012). Para o aproveitamento da ventilação natural, as janelas das salas de aula do Campus do Sertão estão dispostas na mesma direção citada. Todavia, percebe-se que as janelas com grandes dimensões em conjunto com a chaminé tendem a prejudicar o conforto térmico, pois forçam a entrada de ar quente e seco o tempo todo.

Dando continuidade, os benefícios da ventilação natural podem ser ampliados com a utilização de massa com alta inércia térmica, a qual pode ser obtida pela construção de paredes internas e externas com maior massa. Desta maneira, a massa térmica possibilita o atraso do amortecimento térmico e devolução do calor ao meio ambiente durante a noite (ABNT, 2003; ANDRADE, 1996; BARBOSA; LIMA, 2010; MARTINS, et al, 2012). No prédio em análise, as paredes das fachadas são formadas de alvenaria dupla separadas por uma placa de poliestireno expandido, possibilitando o isolamento térmico (SANTOS, 2008).

Semelhante às fachadas, a norma da ABNT (2003) recomenda para a cobertura uma estrutura pesada para evitar a passagem do calor externo para o interior da edificação (ABNT, 2003; BARBOSA; LIMA, 2010; MARTINS, et al, 2012). No edifício em análise, além da laje de concreto armado (Figura 4), existe uma coberta composta por folhas de poliestireno expandido forradas por telhas de alumínio com pintura eletrostática branca.

Assim sendo, afirma-se que a instalação avaliada está de acordo com o que sugere a ABNT (2003), pois no edifício sede do Campus do Sertão foram empregados métodos que evitam a passagem da alta temperatura externa para o interior das salas de aula, no intuito de gerar um adequado ambiente de estudo e economizar energia com processos de condicionamento artificiais.

Posteriormente, verifica-se que as variáveis externas podem contribuir com as técnicas construtivas usadas no supracitado edifício para melhorar o conforto térmico. Neste cenário, a sensação térmica em regiões de clima quente e seco pode ser amenizada 
através da evaporação da água, ou seja, pelo resfriamento evaporativo, a partir do uso de vegetação e outros tipos de fontes de água (BARBOSA; LIMA, 2010).

Desta forma, destaca-se que na edificação analisada, não há processos de resfriamento evaporativo. Todavia, no projeto inicial da instituição, previa-se a construção de um lago na entrada principal do Campus e arborização. Desta maneira, acredita-se que projetos de paisagismo e urbanos ainda devem ser elaborados para a localidade. Sugerese, um plano de arborização, pois o mesmo ajuda a regular a umidade do ar e protege a edificação dos raios solares (BATISTA, 2006; SILVA et al., 2011).

Com base na análise realizada, nota-se que algumas estratégias construtivas para o conforto térmico natural são encontradas no edifício sede do Campus do Sertão da UFAL. Elas preveem o uso da ventilação natural e o isolamento do calor externo para as salas de aula, de modo passivo. Todavia, algumas estratégias, tais como o tamanho das esquadrias, não seguem as recomendações (ABNT, 2003).

\section{CONFORTO LUMÍNICO: ANÁLISE DA ILUMINAÇÃO NATURAL}

A iluminação tem papel fundamental para o desempenho das atividades, pois é através dela que se tem a percepção visual dos espaços e do objeto foco da atenção. Seu correto planejamento contribui para aumentar a satisfação no trabalho, melhorar a produtividade e reduzir a fadiga e os acidentes. No caso de ambientes de aprendizagem, é necessária a visualização perfeita do que está escrito no quadro, além de um nível de iluminância adequado sobre o plano de trabalho de cada aluno (DALVITE et al, 2007).

A boa iluminação compreende características como correto direcionamento e intensidade. Logo, um ambiente com altos índices de luminosidade não é necessariamente iluminado de forma adequada, pois, a luz em demasia pode causar cansaço visual e ofuscamento. Dessa maneira, o projeto de iluminação natural deve se basear na luz solar refletida pelas superfícies do entorno e os dispositivos de iluminação artificial devem ser localizados de modo a minimizar a incidência de luz excessiva.

No mais, a avaliação de conforto lumínico de um ambiente compreende fatores tais como características das aberturas, considerando suas tipologias, dimensões, envidraçamento; fatores de sombra internos ou externos; incidência da luz natural na edificação; características do ambiente interno, tais como cor das superfícies; além da quantidade, disposição e potência das luzes artificiais.

O edifício analisado apresenta iluminação natural unilateral, ou seja, a passagem de luz é realizada através de aberturas (verticais) na alvenaria, as quais estão dispostas em apenas um lado dos ambientes. Entretanto, este tipo de iluminação apresenta desuniformidade na distribuição da luz incidente, já que o nível de iluminância diminui com o aumento da distância da janela (Figura 5). 
Figura 5 - Esquemas de eficiência de iluminação natural unilateral

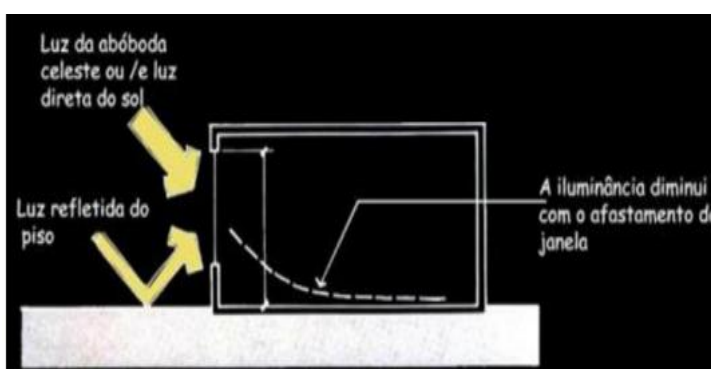

(a)

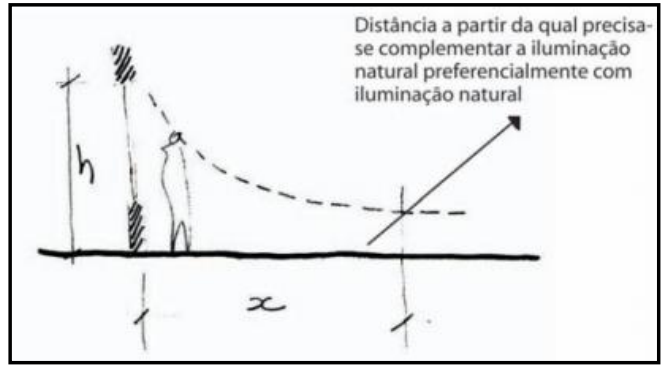

(b)

Fonte: (a) Adaptado de Toledo (2008), e (b) Procel (2011)

Neste caso, considera-se a profundidade de eficiência da penetração da luz como dependente da distância entre o piso e a parte superior da abertura, sendo igual a aproximadamente 1,5 a 2 vezes esta altura (Figura 5). A Tabela 2 apresenta esse cálculo para as salas de aula do Campus do Sertão.

Tabela 2- Profundidade da eficiência de penetração da luz nas salas de aula

\begin{tabular}{|c|c|c|c|c|}
\hline \multirow{2}{*}{$\begin{array}{c}\text { Salas } \\
\text { de aula }\end{array}$} & $\begin{array}{c}\text { Entre o piso e a parte } \\
\text { Superior da janela }\end{array}$ & $\begin{array}{c}\text { Profundidade } \\
\text { de eficiência }(x)\end{array}$ & Largura da sala & $\begin{array}{c}\text { Espaço de } \\
\text { ineficiência }(I)\end{array}$ \\
\hline 01 a 08 & 3,00 & $4,50<\mathrm{x}<6,00$ & 8,40 & $2,40<\mathrm{I}<3,90$ \\
\cline { 1 - 3 } & 09 a 19 & & 7,63 & $3,13<\mathrm{I}<1,63$ \\
\hline
\end{tabular}

Fonte: Elaborado a partir do projeto arquitetônico do Campus do Sertão/UFAL (2009)

Assim, para uma iluminação lateral eficiente em ambientes com essa característica, é preciso que as janelas sejam simétricas e localizadas em lados opostos do ambiente, ou se utilize aberturas zenitais, brises e prateleiras de luz, estratégias as quais regulam a entrada de luz e permitem um maior alcance da mesma (ABNT, 2003; GEMELLI, 2009). Entretanto, tais propostas não foram previstas no projeto deste Campus.

Nesse sentido, destaca-se que prateleiras de luz são dispositivos arquitetônicos utilizados na parte superior de aberturas, sendo formados por planos horizontais ou inclinados (Figura 6a). Este elemento é capaz de promover uma melhor distribuição da luz natural ao longo da profundidade dos ambientes e reduzir o uso de luz artificial. Enquanto os brises são projetados para dar proteção contra ângulos altos do sol (Cândido et al., 2005).

No caso do prédio analisado, optou-se por janelas baixas, contínuas e de grandes dimensões, tanto em altura quanto em comprimento. As mesmas representam em média 46\% da área das paredes onde se localizam (Tabela 3 e Figuras 3, 6b). Logo, há visualização da abóbada celeste e grande penetração da luz natural direta, provocando ofuscamento e reflexos excessivos.

Para o desenvolvimento das atividades de aprendizagem é necessário um contraste adequado sobre os planos de trabalho de alunos e professores. Entretanto, esta variação do nível de iluminação e o ofuscamento nas salas de aulas do Campus provocam perturbação, desconforto e perda de visibilidade. Por vezes, estes fatores demandam maior esforço visual dos estudantes, bem como dificultam o uso de material didático escrito ou projetado no quadro branco, por parte dos docentes. 
Tabela 3 - Relação entre as áreas das aberturas laterais e das alvenarias externas.

\begin{tabular}{|c|c|c|c|}
\hline \multirow{2}{*}{ Salas de aula } & \multicolumn{2}{|c|}{ Áreas $\left(\mathbf{m}^{\mathbf{2}}\right)$} & \multirow{2}{*}{$\begin{array}{c}\text { Percentual das áreas das janelas em } \\
\text { relação à alvenaria }(\%)\end{array}$} \\
\cline { 2 - 3 } & Da parede externa & Das janelas & 51,40 \\
\hline $01 ; 12$ & 25,50 & 13,10 & 42,90 \\
\hline 02 a 07 & 29,40 & 12,60 & 43,70 \\
\hline 09 & 14,40 & 6,30 & 42,9 \\
\hline $10 ; 13$ a 18 & 29,40 & 12,60 & 52,50 \\
\hline 11 & 24,00 & 12,60 & 43,40 \\
\hline 08 e 19 & 25,35 & 11,00 & \\
\hline
\end{tabular}

Fonte: Elaborado a partir do projeto arquitetônico do Campus do Sertão/UFAL (2009)

Figura 6 - (a) Esquema de prateleira de luz e (b) Destaque da incidência solar no quadro branco

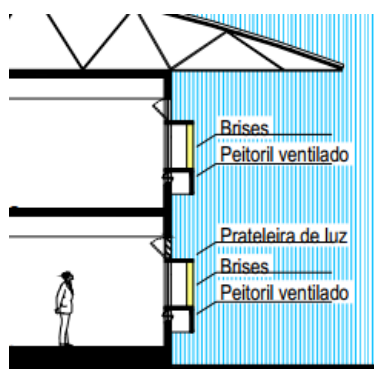

(a)

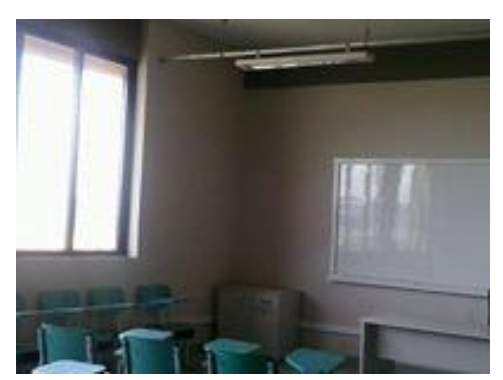

(b)

Fonte: (a) Adaptado de Cândido et al (2005), e (b) Os autores (2012)

Quanto à cor e textura do piso, paredes e teto no interior da referida edificação, nota-se adequação pela utilização de cores claras e uniformes, as quais permitem a reflexão da luz pelo ambiente e favorecem o conforto visual dos usuários. Neste ínterim, o teto é a principal superfície de contribuição para a reflexão da luz e para a quantidade de luz incidente no plano de trabalho. Por isso, adota-se um índice de reflexão de $70 \%$, o que corresponde a cores claras, branco gelo no caso do prédio estudado (PROCEL, 2011).

Além disso, cabe avaliar o envidraçamento das aberturas, cuja função é controlar a quantidade de iluminação. $O$ vidro simples, por exemplo, permite uma alta transmissão natural, cerca de 85\%, acompanhada de energia solar direta (ERG, 1994). No Campus do Sertão, optou-se pela utilização de vidros low-e, os quais reduzem a entrada de energia solar na construção e refletem menos "luz visível". Este envidraçamento resulta na redução de transmissão para 70\% (LOW-E..., 2010), desde que as janelas permaneçam fechadas, apesar de ser uma eficiente estratégia de controle da energia solar por favorecer o aproveitamento da luz natural com redução dos ofuscamentos, dificulta o uso de ventilação natural.

No que tange às necessidades lumínicas de uma sala de aula, é necessário que a iluminação geral seja uniforme. Neste aspecto, observa-se que o prédio analisado não apresenta eficiência da utilização de luz natural no interior de toda a sala. A fim de minimizar esse problema, utiliza-se a iluminação artificial mesmo durante o dia, aumentando o consumo de energia.

\section{CONSIDERAÇÕES FINAIS}

A Arquitetura Bioclimática objetiva melhorar o desempenho das edificações com base nos dados meteorológicos de cada região. Todavia, no Brasil, e principalmente no 
semiárido, percebe-se que a falta de dados nesses aspectos prejudicam o desenvolvimento de estratégias construtivas adequadas à região. Esta problemática realça a necessidade de estudos relacionados ao conforto ambiental para essa localidade.

De modo geral, para a avaliação do Campus do Sertão da UFAL, foram analisadas as referências que melhor se adequam ao clima de Delmiro Gouveia. Assim, o presente trabalho objetivou apresentar uma análise parcial dos aspectos construtivos das salas de aula da referida edificação sob o ponto de vista dos confortos térmico e lumínico.

No que tange ao conforto higrotérmico, o efeito chaminé aliado ao uso de alvenaria dupla com aplicação de poliestireno expandido contribuem, respectivamente, para o condicionamento passivo e amortecimento térmico dos ambientes. Todavia, a ausência de estratégias de resfriamento evaporativo, ventilação seletiva e de sombreamento são considerados pontos negativos.

No conforto lumínico, aspectos como o emprego de cores claras nos revestimentos e o envidraçamento low-e contribuem para utilização de luz natural reflexiva e redução do ofuscamento. Ao passo que são necessárias adequações como o emprego de técnicas para melhor distribuição da luz natural.

No mais, tendo em vista que essa etapa da pesquisa limitou-se aos parâmetros construtivos, propõe-se como pesquisa futura, a realização de uma Avaliação PósOcupação (APO) junto aos atores locais, bem como medições in loco, para uma análise mais criteriosa.

\section{AGRADECIMENTOS}

Ao Programa de Educação Tutorial (MEC/SESu) PET-AÇÕES das Engenharias do Campus do Sertão da UFAL.

\section{REFERÊNCIAS}

AGRITEMPO. Dados históricos - Delmiro Gouveia. Disponível em: <http://www.agritempo.gov.br/agroclima/sumario>. Acesso em: 14 de Agosto de 2012.

ANDRADE, S. F. Estudo de estratégias bioclimáticas no clima de Florianópolis. Dissertação de Mestrado em Engenharia. Universidade Federal de Santa Catarina, Florianópolis, 1996.

ASSOCIAÇÃO BRASILEIRA DE NORMAS TÉCNICAS (ABNT). NBR-15220-3: Desempenho térmico de edificações parte 3: Zoneamento bioclimático brasileiro e diretrizes construtivas para habitações unifamiliares de interesse social. Rio de Janeiro, 2003.

BARBOSA, D. C.; LIMA, M. B. Arquitetura bioclimática: recomendações apropriadas para palmas/TO. In: V CONNEPI - Congresso Norte Nordeste de Pesquisa e Inovação, 2010, Anais... Maceió. 2010. v. 1.

BATISTA, J. O. Arquitetura e seu desempenho térmico no contexto do semi-árido alagoano: estudo de caso em Santana do Ipanema - AL. Dissertação de Mestrado. Universidade Federal de Santa Catarina, Florianópolis, 2006.

BRASIL. Instituto Brasileiro de Geografia e Estatística - IBGE, 2009.

CÂNDIDO, C.; TORRES, S.; CABÚS, R. Análise da utilização de prateleiras de luz em edifícios de pesquisa da UFAL, Maceió-AL. In: Encontro Nacional de Conforto do Ambiente Construído - ENCAC, 2005. Anais... Maceió. 2005.

CHIARELLO, J. A. Ventilação Natural por Efeito Chaminé - Estudo em Modelo Reduzido de Pavilhões Industriais. Dissertação (Mestrado em Engenharia Civil). Universidade Federal do Rio Grande do Sul, Porto Alegre, 2006. 
CORBELLA, O.; YANNAS, S. Em busca de uma arquitetura sustentável para os trópicos: conforto ambiental. Rio de Janeiro: Revan, 2003.

COSTA, G. B.; LYRA, R. F. F. Análise dos padrões de vento no Estado de Alagoas. Revista Brasileira de Metereologia. São Paulo, v. 27, n. 1, p. 21-38, 2012.

DALVITE, B.; OLIVEIRA, D.; NUNES, G.; PERIUS, M.; SCHERER, M. J. Análise do conforto acústico, térmico e lumínico em escolas da rede pública de Santa Maria, RS. Revista Disc. Scientia, Santa Maria, v. 8, n. 1, p. 1-13, 2007.

ENERGY RESEARCH GROUP (ERG). Daylighting in buildings. School of Architecture University College, Dublin, 1994.

GEMELLI, C. B. Avaliação de conforto térmico, acústico e lumínico de edificações escolares com estratégias sustentáveis e bioclimáticas: o caso da Escola Municipal de Ensino Fundamental Frei Pacífico. Dissertação (Mestrado em Engenharia Civil). Universidade Federal do Rio Grande do Sul, Porto Alegre, 2009.

GUTIERREZ, G. C. R.; LABAKI, L. C. Considerações sobre o brise-soleil na arquitetura moderna brasileira. In: VIII Encontro Nacional de Conforto no Ambiente Construído - VIII ENCAC, 2005, Anais... Maceió, AL.

KRÜGER, E. L.; ZANNIN, P. H. T. Acoustic, thermal and luminous comfort in classrooms. Building and Environment 39, p.1055-1063, 2004.

LOW-E: escudo contra o frio, bônus contra o calor. O vidro plano, 454 ed., out. 2010. Disponível em: <http://www.abravidro.org.br/downloads/rep-esp/ovidroplano_454_out2010Low-e.pdf>. Acesso em 14 de set de 2012.

MARTINS, T. A. L.; BITTENCOURT, L. S.; KRAUSE, C. B. Contribuição ao zoneamento bioclimático brasileiro: reflexões sobre o semiárido nordestino. Ambiente Construído (Online), v. 12, p. 59-75, 2012.

Programa Nacional de Conservação de Energia Elétrica - PROCEL. Iluminação natural e artificial. Rio de Janeiro: [S. ed.], 2011.

SANTOS, R. D. Estudo térmico e de materiais de um compósito a base de gesso e EPS para construção de casas populares. (Dissertação). Programa de Pós-Graduação em Engenharia Mecânica. Universidade Federal do Rio Grande do Norte, 2008.

SILVA, S. M. G. M. A sustentabilidade e o conforto das construções.Tese (Doutorado em Engenharia Civil). Escola de Engenharia, Universidade do Minho, Guimarães, 2009.

SILVA, D. B. L.; BARROS, B. R.; AMORIM, J. A. Arborização viária no Sertão Alagoano: Estudo do Bairro Eldorado em Delmiro Gouveia/AL. Encontro Latino-americano sobre Edificações e Comunidade Sustentáveis, 6, 2011. Vitória/ES. Anais...Vitória, 2011

SOUZA, V. M. B. de. A influência da ocupação do solo no comportamento da ventilação natural e na eficiência energética em edificações. Estudo de caso em Goiânia - Clima tropical de altitude. (Dissertação). Departamento de Pós-Graduação da Faculdade de Arquitetura e Urbanismo, Universidade de Brasília, 2006.

TOLEDO, B. G. Integração de iluminação natural e artificial: métodos e guia prático para projeto luminotécnico. Dissertação (Mestrado em Arquitetura e Urbanismo). Programa de PósGraduação em Arquitetura e Urbanismo, Universidade de Brasília, 2008. 